\title{
Laser trabeculoplasty
}

Early attempts at laser treatment of open angle glaucoma met with limited success. Goniopuncture using the Q-switched ruby laser ${ }^{1}$ caused a temporary reduction only of intraocular pressure (IOP), and argon laser photocoagulation of the trabecular meshwork, though producing sustained IOP reductions in some patients, ${ }^{2}$ was accompanied by acute posttreatment rises in others. In $1979 \mathrm{~W}$ ise and Witter reported the successful reduction of IOP with few complications using the argon laser at lower energy levels than before. ${ }^{3}$ They treated the full circumference of the trabecular meshwork applying 100 evenly spaced burns of $50 \mu \mathrm{m}$ spot size at a power of 1000 to $1500 \mathrm{~mW}$ for $0 \cdot 1$ seconds and achieved an average fall in IOP of $10.3 \mathrm{~mm} \mathrm{Hg}$ at 3 months in 41 patients. This success was subsequently confirmed by others and the technique employed today is substantially the same.

\section{Pathophysiology}

Wise and Witter postulated that the fall in IOP was a mechanical effect, the evenly spaced microscars reducing the diameter of the inner trabecular ring and reversing collapse of the meshwork with restoration of normal outflow function. That argon laser trabeculoplasty (ALT) acts by increasing the facility of outflow has been confirmed by tonographic ${ }^{4}$ and fluorophotometric ${ }^{5}$ studies but this mechanical theory, though attractive, has not been supported by animal or enucleated human eye tissue studies. It has also been observed that heat induced shrinkage of the trabecular collagen is a rapid process whereas the time course of the ALT response is relatively slow. ${ }^{6}$

From early histological studies it was clear that successful argon laser treatment was not dependent on the formation of a direct communication between the anterior chamber and Schlemm's canal. Ultrastructural changes seen in trabeculectomy specimens from patients previously treated by ALT include intratrabecular debris, distortion of trabecular beams and death of trabecular endothelial cells, leaving the damaged beams denuded. But there is also evidence of activation and migration of surviving trabecular endothelial cells to the burn site. ${ }^{7}$ In many specimens cellular sheets extending from Schwalbe's line and covering the surface of the anterior meshwork have been observed. These sheets have been considered to represent an excessive repair response which contributes to failure of the laser treatment.

Increased trabecular cell division following ALT at sites distant to the laser burns has also been demonstrated in vitro using organ cultured trabecular meshworks, the majority of the cells originating in the anterior meshwork close to Schwalbe's line. ${ }^{6}$ Two weeks after laser treatment these active cells are concentrated around the burn sites and it has been suggested that they may exert an influence on outflow resistance by causing alterations in the synthesis of the proteoglycan components of the extracellular matrix. ${ }^{8}$

ALT causes a temporary disruption of the blood ocular barrier resulting in aqueous protein flare and there is evidence that this is mediated by prostaglandins which can be synthesised by the trabecular meshwork. Post-ALT flare is maximal at 48 hours and there is a positive correlation at this time between the level of inflammation and IOP decrease which can be partially blocked by prostaglandin synthesis inhibitors. Of particular interest is the finding of Mermoud et $a l^{9}$ that this correlation persists long after the inflammatory reaction has subsided and they considered the possibility that prostaglandin production might persist at a level sufficient to lower the IOP but too low to disrupt the blood ocular barrier.

\section{Technique}

The main treatment variables are the proportion of the angle treated, the size and placement of individual burns, and the energy used. Surprisingly, wavelength appears to be of little importance. No difference between the effect of argon bluegreen and argon green lasers has been found ${ }^{10}$ and the krypton laser, ${ }^{11}$ the diode laser, ${ }^{12}$ and others have all produced results comparable with those of argon.

Treatment of 180 degrees with 50 burns has been found by some investigators ${ }^{1314}$ to be as effective as full 360 degree treatment while producing significantly lower post-treatment IOP rises. Others have achieved greater effect with 360 degree treatment ${ }^{15}$ but this can be more safely carried out in two treatment sessions of 180 degrees each.

The degree of IOP reduction is similar whether burns are placed on the anterior or posterior meshwork ${ }^{16}$ but acute IOP elevation ${ }^{17}$ and peripheral anterior synechiae (PAS) formation are more frequent with posterior placement. The accuracy of placement is facilitated by a small spot size and $50 \mu \mathrm{m}$ has been almost universally used but Sherwood et al ${ }^{18}$ using $150 \mu \mathrm{m}$ and $350 \mu \mathrm{m}$ spots obtained good pressure reduction though the larger spot was difficult to focus.

The effectiveness of ALT is independent of the duration of the burn if the total energy delivered is kept constant. With a duration of 0.1 seconds the effective power range lies between $500 \mathrm{~mW}$ and $1000 \mathrm{~mW}$, lower than that originally used by Wise and Witter. Most authorities advocate adjusting the power level to obtain the minimum visible response of blanching of the meshwork and/or gas bubble formation.

\section{Complications}

The most serious complication of ALT is post-treatment acute elevation of IOP resulting in loss of vision. Some increase in IOP is very common and in one study a rise of more than $5 \mathrm{~mm} \mathrm{Hg}$ occurred in $34 \%$ and of more than $10 \mathrm{~mm}$ $\mathrm{Hg}$ in $12 \%$ of patients who had undergone 180 degree ALT. ${ }^{19}$ The frequency and severity of IOP elevations are increased by the use of higher energy levels, 360 degree treatment, posterior placement of burns, angle pigmentation, and a low preoperative facility of outflow. ${ }^{20}$ Most post-treatment IOP peaks occur within the first 2 hours ${ }^{21}$ but occasionally rises may be delayed and monitoring of IOP for 4 hours has been recommended. The cause of this IOP rise is uncertain but may result from swelling of the trabecular meshwork or obstruction of the trabecular spaces by debris. It is not prevented by steroids or antiprostaglandins but aqueous suppressants and miotics are effective as is apraclonidine, an $\alpha 2$ agonist, which has been found ${ }^{22}$ to reduce the incidence of all pressure rises by nearly two thirds and to eliminate all increases greater than $10 \mathrm{~mm} \mathrm{Hg}$.

PAS develop in a high percentage of patients undergoing ALT but these appear to be of little clinical significance and 
are not associated with a reduced IOP response. They develop more frequently with posteriorly placed burns ${ }^{23}$ and with higher power levels. ${ }^{24}$

Other complications are relatively minor. Corneal endothelial damage has been reported ${ }^{25}$ but prospective studies have failed to show any evidence of morphological or functional damage ${ }^{26}$ and epithelial burns caused by errors of focusing are transient. Similarly uveitis is usually mild and transient but post-treatment topical steroids are often prescribed routinely.

\section{Results of treatment}

ALT significantly reduces IOP in the short term. In one large study a reduction of $6.4 \mathrm{~mm} \mathrm{Hg} \mathrm{(26 \% )} \mathrm{was} \mathrm{found} \mathrm{at} 5$ months in 237 patients with primary open angle glaucoma (POAG) on maximum medical treatment. ${ }^{4} \mathrm{~A}$ greater reduction was obtained using ALT as the primary treatment with a fall of $9.0 \mathrm{~mm} \mathrm{Hg}(33 \%)$ at 3 months in 264 patients with POAG. ${ }^{27}$ Several studies have also shown a beneficial effect of ALT on the diurnal pressure curve with marked reductions of intraindividual IOP fluctuation in successfully treated patients. ${ }^{28}$

From the outset it was recognised that there was some loss of effect of ALT with time. By the mid 1980s it was evident that this loss was considerable. Schwartz et al found that their success rate of $77 \%$ at 2 years had fallen to $46 \%$ at 5 years $^{30}$ and Spaeth and Baez have reported that only one third of their patients with POAG could be considered successfully treated by ALT after 5 years. ${ }^{31}$ Overall failure is highest in the first year and subsequently occurs at a rate approaching $10 \%$ per year. Retreatment of failed eyes that have undergone $\mathbf{3 6 0}$ degree ALT is significantly less successful than with initial treatment and loss of effect is more rapid. Richter et al retreated eyes that had undergone 180 degree ALT and achieved an IOP reduction of more than $3 \mathrm{~mm} \mathrm{Hg}$ in only one third of eyes. ${ }^{32}$

The success of ALT is influenced by patient selection. Patients under 50 years of age respond less well but there is no difference between the sexes. ${ }^{33}$ Black patients initially do as well as white patients ${ }^{34}$ but loss of effect is more rapid with only half as many black patients considered successful after 5 years. ${ }^{30}$ Survival curve analysis has shown the median time to an IOP of $21 \mathrm{~mm} \mathrm{Hg}$ to be 12 months for black patients and 60 months for whites.

The average initial fall in IOP of eyes with POAG is about $30 \%$. The response is more or less linear with the pretreatment pressure and, as might be expected, eyes with normal tension glaucoma show a smaller effect. The results of ALT in pigmentary glaucoma are conflicting with some evidence that older patients do less well, ${ }^{35}$ but overall the response is similar to that of POAG. The largest pressure reductions are seen in eyes with exfoliative glaucoma but there is some evidence that failure occurs earlier than in eyes with $\mathrm{POAG}^{36}$ and the pressure rise may be quite rapid. Other forms of secondary open angle glaucoma generally respond less well with uveitic and developmental glaucomas often showing little or no useful fall in IOP.

\section{The role of ALT in the management of open angle glaucoma}

Laser trabeculoplasty is an outpatient procedure that is well tolerated and relatively safe. It avoids the inconvenience and side effects of medical treatment and the risks of major intraocular surgery. But it also has drawbacks, the greatest of which is the loss of effect with time. Concern has also been raised about the possible adverse effect of ALT on subsequent drainage surgery. The incidence of encapsulated blebs has been found to be up to three times higher in eyes previously treated with ALT. ${ }^{37}$
For a number of years ALT was considered to be a logical next step in the management of open angle glaucoma when maximum tolerable medical treatment had failed to keep the IOP within 'normal' limits or prevent further field loss. ALT was regarded as successful for as long as surgery was delayed and in many studies this has been the criterion of success. More recently the role of ALT as a primary treatment in the management of POAG has been investigated and compared in a number of studies with both medical and surgical treatment.

Prospective trials comparing ALT with medical treatment have given results which appear to favour laser treatment but which must be interpreted with caution. The use of stepped medical regimens and the addition of medications to the treatment of uncontrolled 'laser first' patients makes longer term comparison of the two modalities difficult if not impossible. The Glaucoma Laser Trial Research Group reported in 1990 the results of their laser versus topical medications trial. ${ }^{27}$ These showed a higher percentage of patients controlled by ALT alone at 1 and 2 years $(63 \%$ and $44 \%$ ) than by timolol alone ( $41 \%$ and $30 \%)$. But using any two of three allowed topical medications (timolol, dipivefrin, and pilocarpine) $85 \%$ and $66 \%$ of 'medical' eyes were controlled at 1 and 2 years respectively. The distinction between the two treatments becomes blurred when topical medications are added to failed ALT eyes and it is not easy to draw any firm conclusions. One could argue from the results that at 1 and 2 years medical therapy is better than ALT but the advantage probably lies with those patients who had ALT first because they were likely to avoid miotic therapy and its disadvantages for longer than those starting with timolol.

The advantages of surgery over ALT in controlling IOP are more clear cut. Both Watson et al ${ }^{38}$ and Migdal and Hitching $\mathrm{s}^{39}$ have confirmed the significantly lower pressures that can be achieved with trabeculectomy and the reduced need for subsequent medication.

\section{Summary}

Using the now well established technique ALT is a safe and effective means of lowering IOP in eyes with POAG, pigmentary glaucoma, and exfoliative glaucoma though the effect diminishes with time. Pressure reduction with ALT is seldom greater than $30 \%$ and eyes with an IOP of more than $28 \mathrm{~mm} \mathrm{Hg}$ are unlikely to be controlled for any length of time without additional treatment. ALT is probably most suitable either for older patients whose glaucoma is not well controlled on medical treatment, or for patients with newly diagnosed open angle glaucoma, but without advanced field loss, as a primary treatment or in combination with a non-miotic topical medication. In many it will defer surgery, in some indefinitely.

Department of Ophthalmology,

ROGER COAKES

King's College Hospital

Denmark Hill,

London SE5 9RS

1 Krasnov MM. Laseropuncture of the anterior chamber angle in glaucoma.

Am F Ophthalmol 1973; 75: 674-8.
2 Worthen DM, Wickham MG. Argon laser trabeculotomy. Trans Am Acad Ophthalmol Otolaryngol 1974; 78: 371-5. Ophthalmol Otolaryngol 1974; 78: 371-5.
Wise JB, Witter SL. Argon laser therapy for open-angle glaucoma: a pilot
study. Arch Ophthalmol 1979; 97: 319-22.

4 Thomas JV, Simmons RJ, Belcher CD. Argon laser trabeculoplasty in the presurgical glaucoma patient. Ophthalmology 1982; 89: 187-97.

presurgical glaucoma patient. Ophthalmology 1982; 89: 187-97. aqueous humor dynamics of the human eye. Am $\mathcal{F}$ Ophthalmol 1983; 96: aqueous

6 Bylsma SB, Samples JR, Acott TS, Van Buskirk EM. Trabecular cell division after argon laser trabeculoplasty. Arch Ophthalmol 1988; 106: 544-7.

7 Alexander RA, Grierson I. Morphological effects of argon laser trabeculoplasty upon the glaucomatous human meshwork. Eye 1989; 3: 719-26.

8 Acott TS, Kingley PD, Samples JR, Van Buskirk EM. Human trabecular meshwork organ culture: morphology and glycosaminoglycan synthesis. Invest Ophthalmol Vis Sci 1988; 29: 90-100. 
9 Mermoud A, Pittet N, Herbort CP. Inflammation patterns after laser trabeculoplasty measured with the laser flare meter. Arch Ophthalmol 1992; 110: $368-70$.

10 Smith J. Argon laser trabeculoplasty: comparison of bichromatic and monochromatic wavelengths. Ophthalmology 1984; 91: 355-60.

11 Spurney RC, Lederer CM Jr. Krypton laser trabeculoplasty. A clinical report. Arch Ophthalmol 1984; 102: 1626-8.

12 McHugh D, Marshall J, ffytche TJ, Hamilton PAM, Raven A. Diode laser trabeculoplasty (DLT) for primary open-angle glaucoma and ocular hypertrabeculoplasty (DLT) for primary open-angle glaucoma and ocular hyper-

13 Weinreb RN, Ruderman J, Wilensky JT. Influence of the number of laser burns administered on the early results of argon laser trabeculoplasty. phthalmol 1983; 95: 287-92.

14 Horne DJ, Bollows AR, Hutchinson BT, Allen RC. Argon laser trabeculoplasty for open angle glaucoma. A retrospective study of 380 eyes. Trans $O$ phthalmol Soc UK 1983; 103: 288-95.

15 Elsas T. Primary laser trabeculoplasty a comparison of 50 spots in 180 degrees and 100 spots in 360 degrees of the trabecular meshwork. Acta Ophthalmol (Kbh) 1987; 65: 323-5.

16 Brooks AMV, Gillies WE. Do any factors predict a favourable response to laser trabeculoplasty? Aust Ophthalmol 1984; 12: 149-53.

17 Schwartz LW, Spaeth GL, Traverso C, Greenidge KC. Variation of techniques on the results of argon laser trabeculoplasty. Ophthalmology 1983: 90: 781-4.

18 Sherwood MB, Lattimer J, Hitchings RA. Laser trabeculoplasty as supplementary treatment for primary open angle glaucoma. $\mathrm{Br} \mathcal{F}$ Ophthalmol $1987 ; 71$ : $188-91$

19 Glaucoma Laser Trial Research Group. The Glaucoma Laser Trial 1. Acute effects of argon laser trabeculoplasty on intraocular pressure. Arch Ophthalmol 1989; 107: 1135-42.

20 Keightley SJ, Khaw PT, Elkington AR. The prediction of intraocular pressure rise following argon laser trabeculoplasty. Eye 1987; 1: 577-80.

21 Weinreb RN, Ruderman J, Juster R, Zweig K. Immediate intraocular pressure response to argon laser trabeculoplasty. Am f Ophthalmol 1983; 95: 279-86.

22 Robin AL, Pollack IP, House B, Enger C. Effects of ALO 2145 on intraocular pressure following argon laser trabeculoplasty. Arch Ophthalmol 1987; 105: pressure

23 Traverso CE, Greenidge KC, Spaeth GL. Formation of peripheral anterior synechiae following argon laser trabeculoplasty. Arch Ophthalmol 1984; 102 861-3.

24 Rouhiainen HJ, Terasvirta ME, Tuovinen EJ. Laser power and postoperative intraocular pressure increase in argon laser trabeculoplasty. Arch Ophthalmol 1987; 105: 1352-4.

25 Hong C, Kitazawa Y, Tanishima T. Influence of argon laser treatment of glaucoma on corneal endothelium. Fpn f Ophthalmol 1983, 27: 567-74.

26 Thoming C, Van Buskirk EM, Samples JR. The corneal endothelium after laser treatment for glaucoma. Am f Ophthalmol 1987; 103: 518-22.

27 The Glaucoma Laser Trial Research Group. The Glaucoma Laser Trial (GLT):2. Results of argon laser trabeculoplasty versus topical medications. Ophthalmology 1990; 97: 1403-13.

28 Greenidge KC, Spaeth GL, Fiol-Silva Z. Effect of argon laser trabeculoplasty on the glaucomatous diurnal curve. Ophthalmology 1983; 90: 800-3.

29 Elsas $\mathrm{T}$, Junk $\mathrm{H}$, Johnson $\mathrm{H}$. Diurnal intraocular pressure after successful primary laser trabeculoplasty. Am ₹ Ophthalmol 1991; 112: 67-9.

30 Schwartz AL, Love DC, Schwartz MA. Long-term follow up of argon laser trabeculoplasty for uncontrolled glaucoma. Arch Ophthalmol 1985; 103: trabecu

31 Spaeth GL, Baez KA. Argon laser trabeculoplasty controls one third of cases of progressive, uncontrolled, open angle glaucoma for 5 years. Arch Ophthalmol 1992; 110: 491-4.

32 Richter CU, Shingleton BJ, Bellows AR, Hutchinson BT, Jacobson AP. Retreatment with argon-laser-trabeculoplasty. Ophthalmology 1987; 94 1085-9.

33 Grinich NP, Van Buskirk EM, Samples JR. Three year efficacy of argon laser trabeculoplasty. Ophthalmology 1987; 94: 858-61

34 Schwartz AL, Whitten ME, Bleiman B, Martin D. Argon laser trabeculoplasty in uncontrolled phakic open-angle glaucoma. Ophthalmology 1981;88: 203-12.

35 Lunde MW. Argon laser trabeculoplasty in pigmentary dispersion syndrome with glaucoma. Am F Ophthalmol 1983; 96: 721-5.

36 Higginbotham EJ, Richardson TM. Response of exfoliation glaucoma to laser trabeculoplasty. Brf Ophthalmol 1986; 70: 837-9.

37 Richter CU, Shingleton BJ, Bellows AR, Hutchinson BT, O'Connor T, Brill I. The development of encapsulated filtering blebs. Ophthalmology 1988; 95 : Watson PG, Allen ED, Graham CM, Porter GP, Pickering MS. Argon laser trabeculoplasty or trabeculectomy. A prospective randomised block study. trabeculoplasty or trabeculectomy. A prospect

39 Migdal C, Hitchings R. Control of chronic simple glaucoma with primary medical, surgical and laser treatment. Trans Ophthalmol Soc UK 1986; 105: 653-6. 